\title{
Multi-Functional Luminescent Coating for Wood Fabric Based on Silica Sol-Gel Approach
}

\author{
Ming Li ${ }^{1,2,3,{ }^{\dagger}}$, Rui Huang ${ }^{1,2,3,{ }^{\dagger}}$, Zhengquan Fu ${ }^{1,2,3}$, Di Wang ${ }^{1,2,3, * \mathbb{C}}$, Chengyu Wang ${ }^{1,2,3}$ and Jian Li ${ }^{1,2,3}$ \\ 1 Engineering Research Center of Advanced Wooden Materials (Ministry of Education), \\ Northeast Forestry University, Harbin 150040, China; alexlavie@outlook.com (M.L.); \\ huangrui9759@163.com (R.H.); fzq@nefu.edu.cn (Z.F.); wangcy@nefu.edu.cn (C.W.); nefujianli@163.com (J.L.) \\ 2 Key Laboratory of Bio-Based Material Science and Technology (Ministry of Education), \\ Northeast Forestry University, Harbin 150040, China \\ 3 Collage of Material Science \& Engineering, Northeast Forestry University, Harbin 150040, China \\ * Correspondence: diwang1030@nefu.edu.cn; Tel.: +86-186-4506-5081 \\ + These authors contributed equally to the work.
}

Citation: Li, M.; Huang, R.; Fu, Z.; Wang, D.; Wang, C.; Li, J.

Multi-Functional Luminescent Coating for Wood Fabric Based on Silica Sol-Gel Approach. Polymers 2021, 13, 127. https://doi.org/ $10.3390 /$ polym 13010127

Received: 3 December 2020 Accepted: 28 December 2020 Published: 30 December 2020

Publisher's Note: MDPI stays neutral with regard to jurisdictional clai$\mathrm{ms}$ in published maps and institutional affiliations.

Copyright: $(2020$ by the authors. Licensee MDPI, Basel, Switzerland. This article is an open access article distributed under the terms and conditions of the Creative Commons Attribution (CC BY) license (https:// creativecommons.org/licenses/by/ $4.0 /)$.

\begin{abstract}
Environmentally friendly protection coatings have obtained increasing attention for their use in wooden materials, which can be destroyed easily when exposed to outdoor environments. A series of silane sol coatings coordinated with $\mathrm{Eu}^{3+}$ was prepared by hydrolyzing silane compounds. The obtained luminescent coating with three-dimensional net structure showed excellent optical, anti-ultraviolet aging, and thermal stability. The hybrid silane-modified compound coating was welldistributed on the wood by $\mathrm{Si}-\mathrm{O}$ bonds to prevent its removal. The compound coating could stave off the decomposition of wood by converting ultraviolet light into red light and a charring action can endow the wood with thermal stability at high temperature, demonstrating the improvement of fire resistance and radiation residence following prolonged exposure to ultraviolet light, proving its excellent anti-ultraviolet aging properties.
\end{abstract}

Keywords: photoluminescence; thermal stability; optical properties; anti-ultraviolet aging properties

\section{Introduction}

Wood is a natural material mostly composed of cellulose, lignin, and hemicellulose, which is uneven distributed in the cell and intercellular layer [1-4]. Therefore, the wood contains a large number of hydroxyl groups, which are susceptible to water to cause the damage of the wood. What is more, abundant biological characteristics will also make it vulnerable to attacks by organisms and microorganisms in the environment, affecting its stability and applications [5]. Over the years, in the development and utilization of wood products, outdoor use of wood products gradually increased wood surface in the surrounding environment. In recent years, wood products used outdoors have gradually increased. Functional modification of wooden composites has long been a common trend because of their wide applications in homes, heating, furniture, and paper [6]. However, wooden materials easily decompose when exposed with solar radiation and vapor in the air under normal temperature conditions. Thus, it is of great significance to develop sustainable and costeffective coatings to achieve thermal stability and anti-ultraviolet properties.

Although the luminescence efficiency of rare earth are so low due to their parity forbidden 4f-4f transitions, the drawback could be conquered through the introduction of the ligand to form the rare earth complex [7]. The luminescence process of rare-earth complexes can be describe as an energy transfer process that after the formation of singlet excited state molecules attributed to energy absorption through the irradiation of excitation light, the singlet excited state energy is transferred to the triplet state by non-radiative transition, next to which the triplet energy is transferred to the rare earth ions' excited state without radiation together with the radiation process from the excited state of metal 
ions to ground state resulting in light emission. This process of absorbing energy from the ligand and then transferring the energy to the rare earth ions is also called the antenna effect [8]. Rare earth complexes are widely used because of their narrow spectral band, high luminous efficiency, and strong color purity [9].

The degree of aging of the wood composite material depends on the sensitivity of the surface of the material to sunlight, which is related to the chemical structure of the material. Due to the refraction and scattering of light, only a small part of the sunlight shines on the ground, and its wavelength is approximately between $290-430 \mathrm{~nm}$, and the sunlight that negatively affects the surface of the material. Ultraviolet (UV) light irradiation in sunlight can mostly degrade the structure of wood and generate great amount of free radicals, a phenomenon that is mostly attributed to the lignin in the wood, which is so sensitive that it can react with oxygen under certain conditions outdoors to produce chromophoric carbonyl and carboxyl groups, leading to the color change of the wood [10-14]. Traditional organic coatings inevitably decompose when exposed to ultraviolet light for a long time [15]. Functional treatment of wooden materials has long been a major issue because of their massive application in everyday life and high hygroscopicity and decomposition which make their service life greatly shorten.

Organosilicon, a kind of synthetic polymer, whose main chain skeleton is formed by alternating oxygen and silicon atoms connected with other organic segments or functional groups, has been widely used in various fields, including construction, packaging, transportation, medical equipment, and other industries [16-19]. It has become an indispensable type of new polymer material used in daily life and has a superior high temperature resistance performance and anti-ultraviolet aging properties [20,21]. Moreover, to strengthen these anti-ultraviolet aging properties, we introduce rare earth ions dipped in coatings in order to form a coordinated environment to convert the UV light absorbed by photosensitive chromophores into harmless red-light emission by $\mathrm{Eu}^{3+}$ in order to prevent the decomposition process [22]. In addition, the coordination of $\mathrm{Eu}^{3+}$ ions with $-\mathrm{C}=\mathrm{O}$ groups of the ligand will increase the degree of crosslinking of the coating network [23,24].

Herein, multi-functional luminescent protection coatings were prepared by hydrolysis and condensation reactions among the modified silane monomers coordinated with europium (III) ions. The coating composite was obtained through a condensation reaction between the silicon hydroxyl groups in the coating and the surface hydroxyl group of the wood surface as shown in Scheme 1. Mass spectra were measured using electrospray ionization mass spectra (ESI-MS) in the positive mode from tetrahydrofuran solutions. The surface morphology structures were explored by scanning electron microscopy (SEM), Energy Dispersive X-ray Analysis (EDXA), and FTIR spectroscopy (FTIR). Derivative thermogravimetry (DTG) and thermogravimetry (TG) analysis is used to certify the pyrolysis reactions of coated wooden composites from room temperature to $800{ }^{\circ} \mathrm{C}$ to investigate their thermal stability. In addition, the anti-ultraviolet aging ability of the coating composites was also predicted.

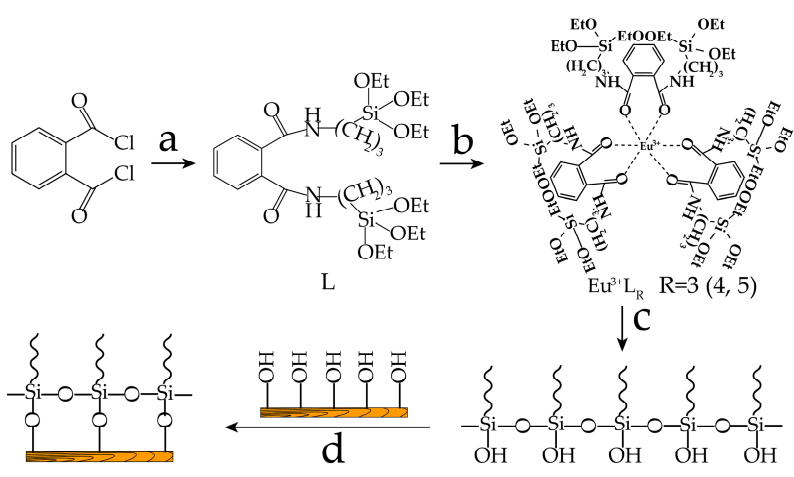

Scheme 1. Synthetic routes to coating composites. (a) aminopropyl trimethoxy silane $/ \mathrm{CH}_{2} \mathrm{Cl}_{2} /$ room temperature, $2 \mathrm{~h} \mathrm{(b)} \mathrm{Eu}\left(\mathrm{NO}_{3}\right)_{3} 6 \mathrm{H}_{2} \mathrm{O} / \mathrm{C}_{2} \mathrm{H}_{5} \mathrm{OH} / 80^{\circ} \mathrm{C}, 8 \mathrm{~h}$ (c) $\mathrm{HCl} / \mathrm{H}_{2} \mathrm{O} / \mathrm{C}_{2} \mathrm{H}_{5} \mathrm{OH} / 40-60{ }^{\circ} \mathrm{C}, 12 \mathrm{~h}$ (d) room temperature, $24 \mathrm{~h} / 85^{\circ} \mathrm{C}, 2 \mathrm{~h}$. 


\section{Materials and Methods}

\subsection{Materials}

Poplar wood slices with the sizes of $10 \mathrm{~mm}$ (longitudinal) $\times 5 \mathrm{~mm}$ (tangential) $\times 2 \mathrm{~mm}$ (radial) were ultrasonically washed in acetone, ethanol and deionized water three times for $10 \mathrm{~min}$ in turn and dried at $50{ }^{\circ} \mathrm{C}$ for $48 \mathrm{~h}$ in a vacuum. Europium nitrate hexahydrate $\left(\mathrm{Eu}\left(\mathrm{NO}_{3}\right)_{3} \cdot 6 \mathrm{H}_{2} \mathrm{O}\right)(99.99 \%)$ and aminopropyl trimethoxy silane $(99 \%)$ used throughout the research were provide by Beijing Huaweiruike Co., Ltd., Beijing, China. Ethanol (99.7\%) and phthaloyl chloride (98\%) were supplied by Tianjin Kaitong Chemical Reagent Co., Ltd. (Tianjin, China) without further purification.

\subsection{Synthesis of Modified Silane Monomer}

Phthaloyl chloride $(0.005 \mathrm{~mol})$ in methylene chloride $(10 \mathrm{~mL})$ was added to the solution of aminopropyl trimethoxy silane $(0.01 \mathrm{~mol})$ in methylene chloride $(10 \mathrm{~mL})$ at $0{ }^{\circ} \mathrm{C}$. Then, the mixture was stirred at room temperature for $2 \mathrm{~h}$, after which the solution were put into a vacuum at $45^{\circ} \mathrm{C}$ to remove the solvent. At last, the colorless and transparent product was obtained

\subsection{Synthesis of Europium Coordination Complex}

$\mathrm{Eu}\left(\mathrm{NO}_{3}\right)_{3} \cdot 6 \mathrm{H}_{2} \mathrm{O}$ and modified silane monomer were accurately weighed with different molar ratios $(1: 3,1: 4,1: 5)$ and dissolved in $10 \mathrm{~mL}$ of anhydrous ethanol. Then, the mixture was heated continuously under reflux at $80^{\circ} \mathrm{C}$ for $8 \mathrm{~h}$ to obtain the complex solution.

\subsection{Synthesis of Organosilicon Sol Coordinated by Europium (III)}

$\mathrm{Eu}\left(\mathrm{NO}_{3}\right)_{3} \cdot 6 \mathrm{H}_{2} \mathrm{O}$ and modified silane monomer were accurately weighed with different molar ratios $(1: 3,1: 4,1: 5)$ and dissolved in $10 \mathrm{~mL}$ of anhydrous ethanol, respectively. Then, the mixture was heated continuously under reflux at $80{ }^{\circ} \mathrm{C}$ for $8 \mathrm{~h}$. Finally, the mixture was diluted with ethanol for concentrations of $0.08 \mathrm{~mol} / \mathrm{L}$. The appropriate amount of distilled water and 4-8 drops of $1 \mathrm{~mol} / \mathrm{L}$ dilute hydrochloric acid were added to the complex's solution above and stirring magnetically in a water bath $\left(40^{\circ} \mathrm{C}, 45^{\circ} \mathrm{C}, 50^{\circ} \mathrm{C}\right.$, $55^{\circ} \mathrm{C}, 60^{\circ} \mathrm{C}$ ) with reflux condensation and stirring for $12 \mathrm{~h}$ to obtain the sol coatings.

\subsection{Synthesis of Coating Composites}

The pre-treated woods were immersed into the $20 \mathrm{~mL}$ of sol coatings at room temperatures under continuous mechanical stirring for $24 \mathrm{~h}$ and a layer of Si-O-Si network structure covered on wood surface by $\mathrm{Si}-\mathrm{O}$ covalent bond. Then, the samples were dried at $85{ }^{\circ} \mathrm{C}$ for over $2 \mathrm{~h}$ in the vacuum. Finally, the coating composites were obtained.

\subsection{Artificial Ultraviolet Aging Test}

Various samples simulated ultraviolet aging under ultraviolet light of high energy in the same conditions to investigate the sol coating composites with radiation time ranging from 0 to $20 \mathrm{~d}$. During the color change test, the color variation of the coating composites surface before and after the UV irradiation were measured with CIELAB system in accordance with the ISO-2470 standard. CIELAB L*, $a^{*}, b^{*}$, parameters were measured at 10 locations on each specimen and every sample had three replicas.

$$
\begin{aligned}
& \Delta \mathrm{L}^{*}=\mathrm{L} 1^{*}-\mathrm{L} 0^{*} \\
& \Delta \mathrm{a}^{*}=\mathrm{a} 1^{*}-\mathrm{a} 0^{*} \\
& \Delta \mathrm{b}^{*}=\mathrm{b} 1^{*}-\mathrm{b} 0^{*}
\end{aligned}
$$

where $\Delta \mathrm{L}^{*}, \Delta \mathrm{a}^{*}$, and $\Delta \mathrm{b}^{*}$ values were the difference of the final $\left(\mathrm{L} 1^{*}, \mathrm{a} 1^{*}, \mathrm{~b} 1^{*}\right)$ and initial $\left(\mathrm{LO}^{*}, \mathrm{a} 0^{*}, \mathrm{~b} 0^{*}\right)$ color values after and before UV irradiation, respectively. 
The values above were used to obtain the overall color change parameter $\Delta \mathrm{E}^{*}$ as a function of the weathering time:

$$
\Delta \mathrm{E}^{*}=\left[\left(\Delta \mathrm{L}^{*}\right)^{2}+\left(\Delta \mathrm{a}^{*}\right)^{2}+\left(\Delta \mathrm{b}^{*}\right)^{2}\right]^{1 / 2}
$$

A small $\Delta \mathrm{E}^{*}$ value was corresponded to a subtle color difference indicating strong resistance of coating composite to UV radiation.

\section{Results}

\subsection{Structural Characteristics}

FTIR spectra of the untreated wood, the coating wood, and the coating composite under UV light radiation for $480 \mathrm{~h}$ was shown in Figure 1. For the untreated wood sample, the peak appears at $3336 \mathrm{~cm}^{-1}$ was assigned to the stretching vibration of the $\mathrm{O}-\mathrm{H}$ stretching groups $[25,26]$. After modification, the intensity of broad absorption peak appeared at $3336 \mathrm{~cm}^{-1}$ became weak, which indicated that a condensation reaction between the silanol groups of hydrolyzed aminopropyl trimethoxy silane and the surface hydroxyl group of the wood surface had occurred [27]. The absorption band at $2913 \mathrm{~cm}^{-1}$ corresponds to the $\mathrm{C}-\mathrm{H}$ stretching vibrations. In addition, after the surface was covered by the sol coating, new adsorption bands appear at $1657 \mathrm{~cm}^{-1}$ and $1730 \mathrm{~cm}^{-1}$, which is attributed to $\mathrm{C}=\mathrm{O}$ stretching vibrations and $\mathrm{N}-\mathrm{H}$ bending vibration, respectively [28], proving the existence of a secondary amide group on the coating surface. The peaks around $1025 \mathrm{~cm}^{-1}$ corresponded to $\mathrm{Si}-\mathrm{O}-\mathrm{Si}$ and $\mathrm{Si}-\mathrm{O}-\mathrm{C}$ stretching vibrations after coating [29]. The absorption peak at $1092 \mathrm{~cm}^{-1}$ was ascribed to the $\mathrm{Si}-\mathrm{O}-$ wood bond, indicating a strong polycondensation grafting reaction between silanol groups and the wood surface [30]. More importantly, the curves of the wood after a long period of radiation exposure exhibited similar behavior in relation to their FTIR spectra compared with the coating composite, which proves the ability of the sol coating to protect wood from ultraviolet light damage.

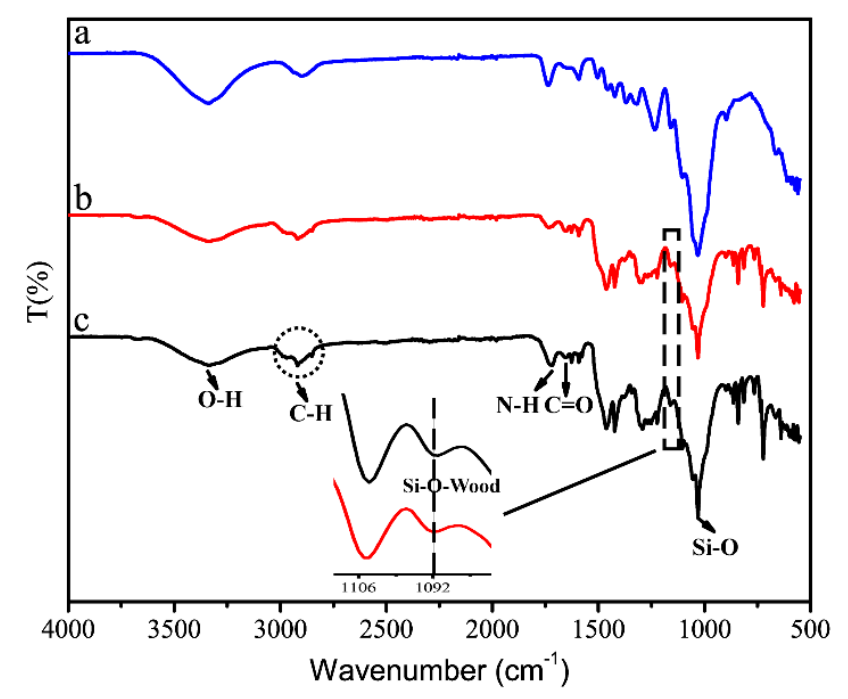

Figure 1. FT-IR spectra for (a) the untreated wood, (b) the sol coating composite, (c) the sol coating composite under UV-light radiation $(340 \mathrm{~nm})$ for $480 \mathrm{~h}$.

The ESI-MS spectra of organosilicon sol coordinated by europium (III) in the positive mode are shown in Figures S1 and S2 in the supplementary material. The spectra exhibit peaks at $\mathrm{m} / \mathrm{z}=630.05$ and 721.07 that are assigned to the ligands (see Supplemental Information, Figure $\mathrm{S} 1$ in the supplementary material), verifying the formation of $\mathrm{Si}-\mathrm{O}$ structure. In addition, several fragments containing europium were observed in the mass spectra (Table S1 in the supplementary material). 


\subsection{SEM-EDX Analysis}

The SEM results in Figure 2 exhibit the surface morphologies of the untreated wood, the sol coating composite, and the sol coating composite under UV light radiation ( $340 \mathrm{~nm})$ for $480 \mathrm{~h}$. In Figure 2a, the pristine tracheid of the wood is smooth. A homogeneous and continuous network structure masks the surface (Figure 2b), which is attributed to the sol-gel reaction on the silane, indicating that the sol coatings were effectively applied to the wood surface. The chemical elements on the surface were explored using their EDXA spectra, as shown in Figure 3. Before treating the wood, there are only carbon, oxygen, nitrogen, and gold elements that could be detected. After coating, silicon, europium, and chloride could be found from the spectra due to the introduction of the sol coating. The element distribution of the coating composite changed slightly under UV radiation over the $480 \mathrm{~h}$, from which it could be predicted that part of the coating was subject to strong radiation during its protection of the wood surface. As shown in Figure 2c, after a long period of radiation exposure, the coating structure protecting the wood partially disappeared.

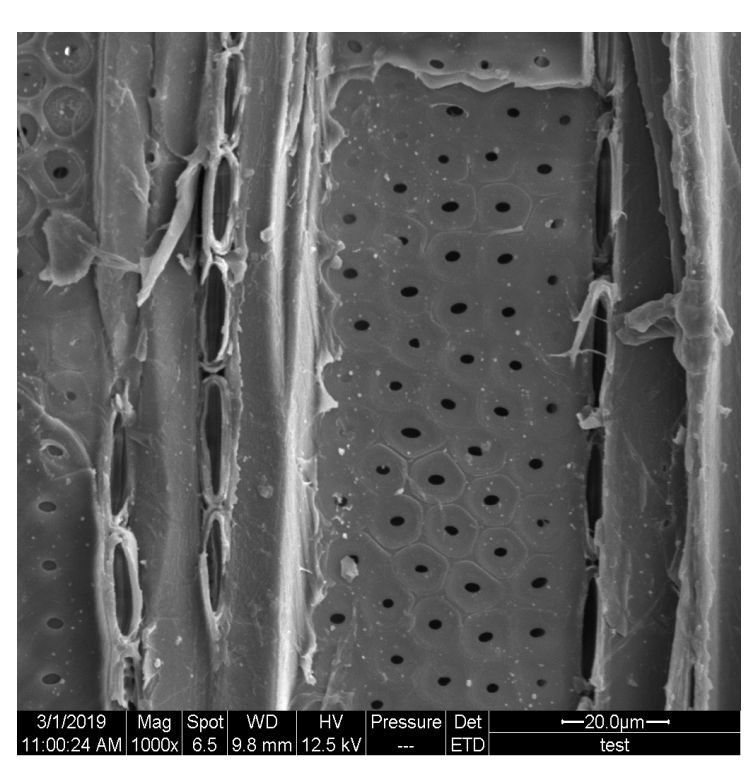

(a)

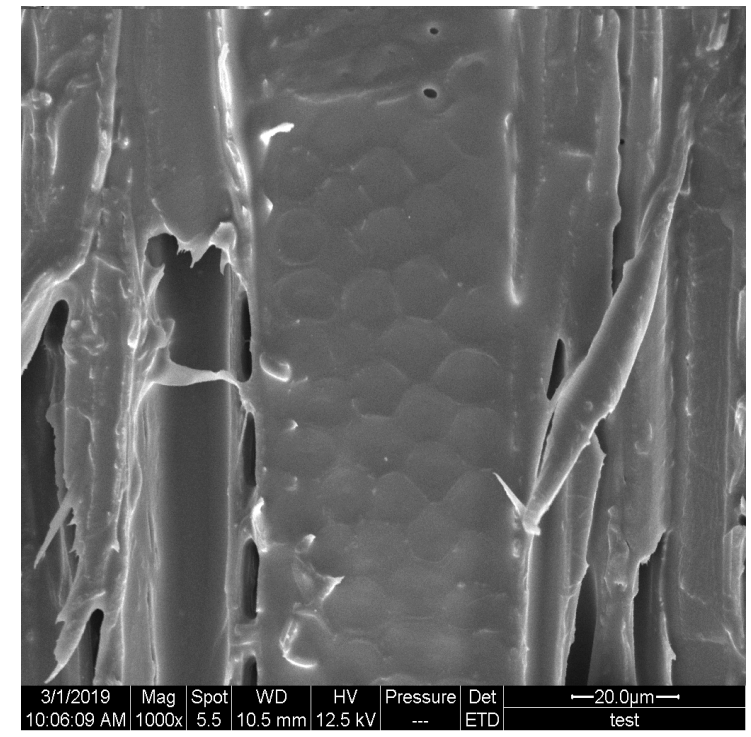

(b)

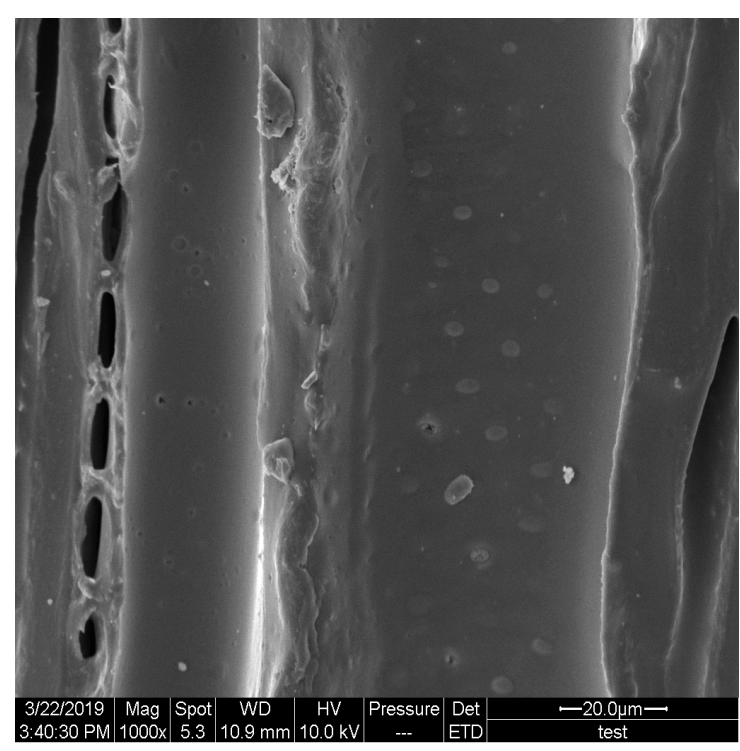

(c)

Figure 2. SEM spectra of (a) the untreated wood, (b) the sol coating composite, (c) and the sol coating composite under UV light radiation $(340 \mathrm{~nm})$ for $480 \mathrm{~h}$. 
(a)

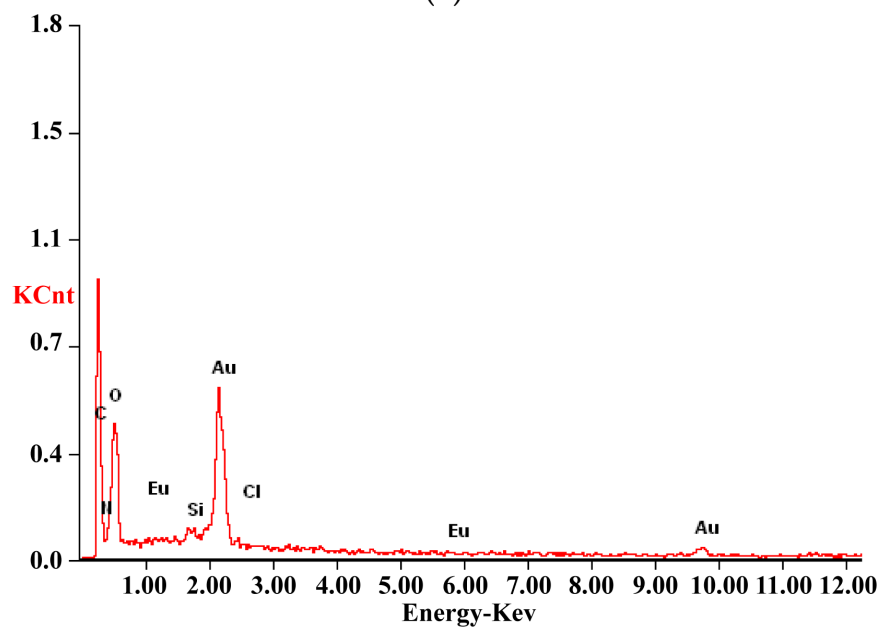

(b)

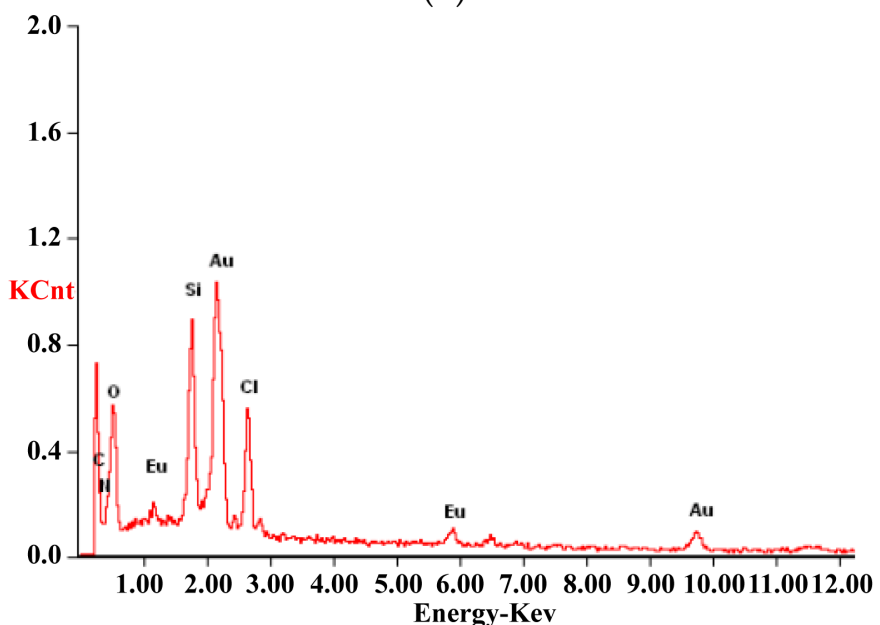

(c)

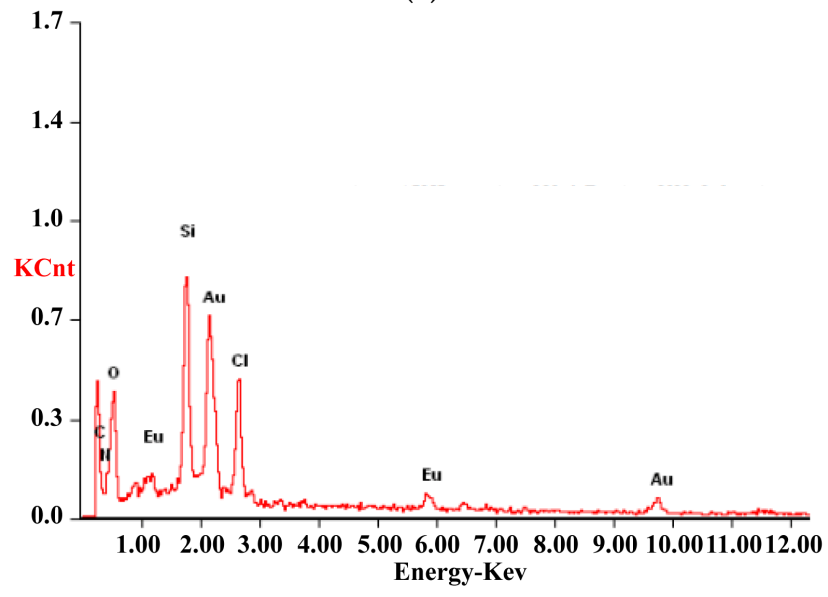

Figure 3. Energy Dispersive X-ray Analysis (EDXA) spectra of (a) the untreated wood, (b) the sol coating composite, (c) and the sol coating composite under UV light radiation $(340 \mathrm{~nm})$ for $480 \mathrm{~h}$.

\subsection{Thermal Stability}

For untreated wood, there are four thermal degradation steps that have been clearly observed in the $\mathrm{N}_{2}$ atmosphere (Figure 4). The first step occurred below $120^{\circ} \mathrm{C}$ and the subtle weight loss could be attributed to the loss of water. The most weight loss happened in the second region from 120 to $400{ }^{\circ} \mathrm{C}$, and was caused by the depolymerization of the hemicellulose, giving rise to D-xylose as well as to some oligosaccharide mixtures. Then, further oxidation of the lignin took place at a higher temperature [31,32]. Compared with the untreated wood, as shown in Figure 4 and Table 1, the introduction of the sol coating increased the decomposition process of the wood with lower $T_{\max 2}$ values, which could be attributed to the stable thermal silicide layer initially generated by the reaction of hydroxyl and silane hydroxyl. The initial degradation was conducive to improving the thermal stability of the wood as stable thermal silicious structures formed, which could postpone the next stage of its degradation. Although the thermal stability of the coating on the wood was reduced at the beginning, it was significantly strengthened in the last decomposition step, which could also be indicated by the elevated $\mathrm{T}_{\max 3}$ value and increased residue from 600 to $800{ }^{\circ} \mathrm{C}$. 
(a)

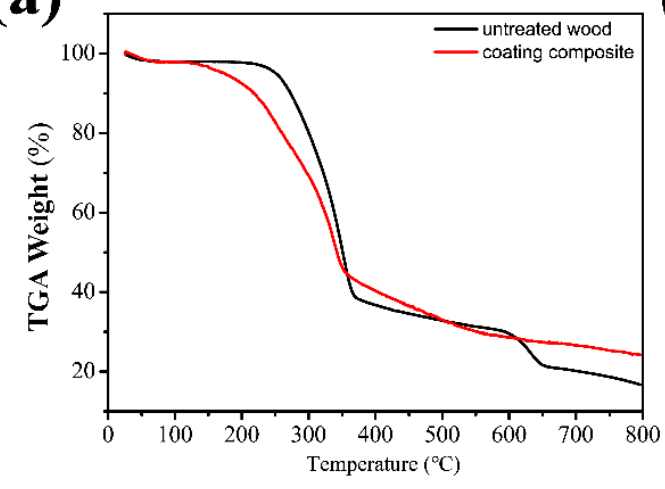

(b)

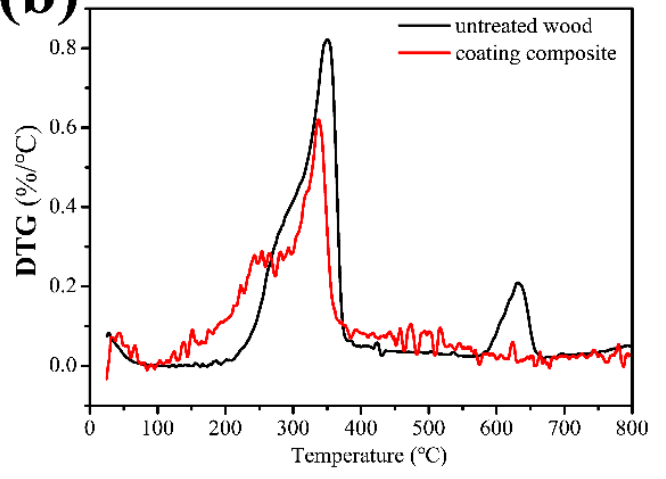

Figure 4. TGA curves (a) and DTG curves (b) for the untreated wood and coating composite.

Table 1. Results of thermogravimetric analysis.

\begin{tabular}{|c|c|c|c|c|c|c|c|c|c|c|}
\hline Sample & $\begin{array}{c}\mathrm{T}_{\max 1} \\
\left({ }^{\circ} \mathrm{C}\right)\end{array}$ & $\begin{array}{l}\text { Residue at } \\
120^{\circ} \mathrm{C}(\%)\end{array}$ & $\begin{array}{c}\mathrm{T}_{\max 2} \\
\left({ }^{\circ} \mathrm{C}\right)\end{array}$ & $\begin{array}{l}\text { Residue at } \\
400^{\circ} \mathrm{C}(\%)\end{array}$ & $\begin{array}{c}\mathrm{T}_{\max 3} \\
\left({ }^{\circ} \mathrm{C}\right)\end{array}$ & $\begin{array}{l}\text { Residue at } \\
600^{\circ} \mathrm{C}(\%)\end{array}$ & $\begin{array}{l}\mathrm{T}_{\max 4} \\
\left({ }^{\circ} \mathrm{C}\right)\end{array}$ & $\begin{array}{l}\text { Residue at } \\
700{ }^{\circ} \mathrm{C}(\%)\end{array}$ & $\begin{array}{c}\mathrm{T}_{\max 5} \\
\left({ }^{\circ} \mathrm{C}\right)\end{array}$ & $\begin{array}{c}\text { Residue at } \\
800^{\circ} \mathrm{C} \\
(\%)\end{array}$ \\
\hline $\begin{array}{l}\text { Untreated } \\
\text { wood }\end{array}$ & 69.2 & 98.0 & 370.7 & 36.8 & 596.8 & 29.6 & 651.4 & 20.2 & 800 & 16.7 \\
\hline $\begin{array}{l}\text { Coating } \\
\text { composite }\end{array}$ & 72.2 & 97.7 & 354.3 & 40.3 & 573.1 & 28.6 & - & 26.6 & 800 & 24.2 \\
\hline
\end{tabular}

\subsection{Aging Property and Optical Stability}

The color variations during the UV light $(340 \mathrm{~nm})$ radiation were measured via accelerated aging tests to explore the anti-ultraviolet property of the wood as well as the coating composite. UV aging resistance was predicted by the $\Delta \mathrm{E}^{*}$ before and after UV radiation. It can be seen that the $\Delta \mathrm{E}^{*}$ value of the untreated wood is higher than the coating composite. Figure 5a shows the trends of the $\Delta \mathrm{E}^{*}$ in the samples with sol coatings obtained under different reaction temperatures $\left(40^{\circ} \mathrm{C}, 45^{\circ} \mathrm{C}, 50^{\circ} \mathrm{C}, 55^{\circ} \mathrm{C}, 60^{\circ} \mathrm{C}\right)$ before and after $\mathrm{UV}$ light radiation. The $\Delta \mathrm{E}^{*}$ of the sample coated with the sol coating obtained at $60{ }^{\circ} \mathrm{C}$ is the lowest, predicting that the UV aging resistance of the sample is proportional to the reaction temperature of the sol coating. The photochromic performance of the coating composite becomes gradually stable with the UV exposure time increasing. The wood with coatings obtained at $60{ }^{\circ} \mathrm{C}$ exhibited a stronger UV resistance ability. As an important indicator of the service life of the material, the $\Delta \mathrm{E}^{*}$ values play a necessary part.
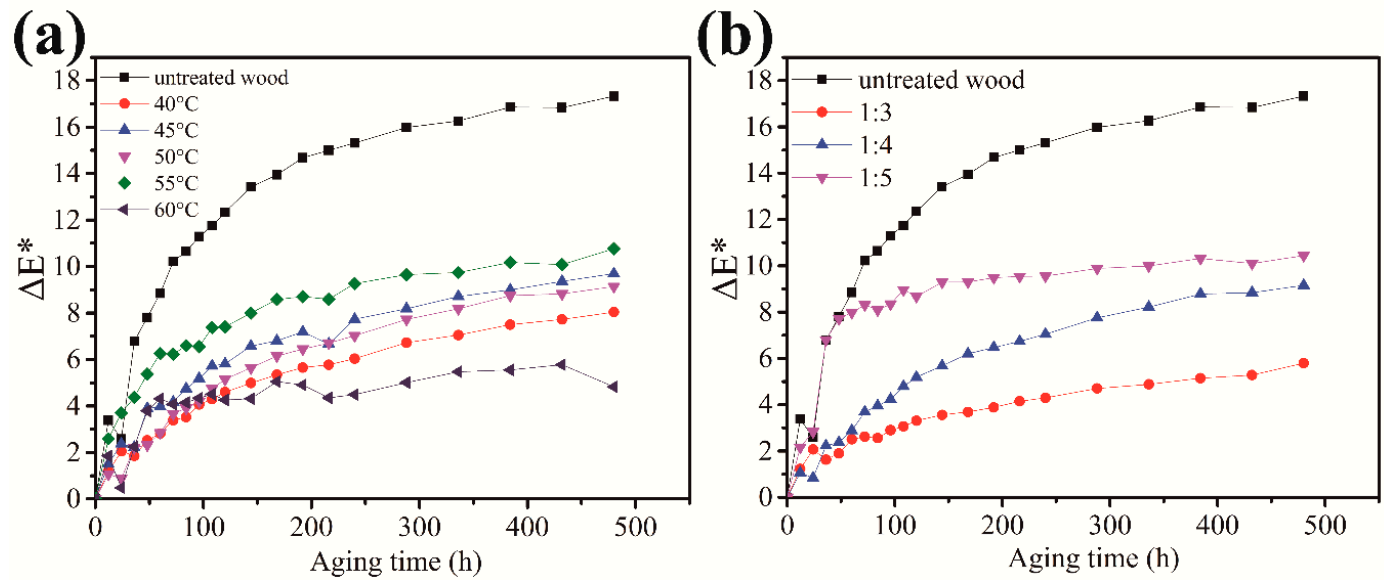

Figure 5. Variation tendency of $\Delta \mathrm{E}^{*}$ of the untreated wood and coating composite with sol coatings obtained under (a) different reaction temperatures $\left(40^{\circ} \mathrm{C}, 45^{\circ} \mathrm{C}, 50{ }^{\circ} \mathrm{C}, 55^{\circ} \mathrm{C}, 60^{\circ} \mathrm{C}\right)(\mathbf{b})$ different ratio between $\mathrm{Eu}^{3+}$ and ligands. 
Figure $5 \mathrm{~b}$ shows the $\Delta \mathrm{E}^{*}$ of the untreated wood and coating composite under UV light radiation in relation to the variability of the different ratios between $\mathrm{Eu}^{3+}$ and ligands. After $480 \mathrm{~h}$ of UV light radiation, the $\Delta \mathrm{E}^{*}$ values of all coating composites exhibited no significant fluctuations and only slight variations, indicating the good photochromic stability of the sol coating. A ratio of 1:3 showed the best UV light resistance with less color variation. Meanwhile, the largest ratio for the changing values of natural wood and modified wood is 6.29 , which belongs to the ratio 1:3 and approaches two times that of the ratio 1:4. The ratio between $\mathrm{Eu}^{3+}$ and the ligands of 1:3 was the most stable after $100 \mathrm{~h}$ of aging for this variable.

To further investigate the optical properties of the coating composite under sustained $\mathrm{UV}$ radiation $(340 \mathrm{~nm})$, the variations in the values of the emission peaks of $\mathrm{Eu}^{3+}(614 \mathrm{~nm})$ in the coating composites obtained at the most optional conditions with a ratio of 1:3 at $60{ }^{\circ} \mathrm{C}$ were evaluated. As shown in Figure 6, it can be seen that, after ultraviolet radiation, the fluorescence of wood is enhanced, which is perhaps due to the fact that, after a long period of radiation exposure, the silane undergoes further hydrolysis and condensation reactions, leading to the formation of an $\mathrm{Si}-\mathrm{O}$ network structure, which will increase the rigidity of the ligand and reduce the energy loss by non-radiative deactivation [33]. On the contrary, the condensation reaction of organic-inorganic hybrid coatings change the coordination environment of $\mathrm{Eu}^{3+}$, which could be reflected by the ratio of ${ }^{5} \mathrm{D}_{0} \rightarrow{ }^{7} \mathrm{~F}_{2}$ $(614 \mathrm{~nm})$ transition to ${ }^{5} \mathrm{D}_{0} \rightarrow{ }^{7} \mathrm{~F}_{1}(590 \mathrm{~nm})$ transition [34-36]. The larger ratio of ${ }^{5} \mathrm{D}_{0} \rightarrow{ }^{7} \mathrm{~F}_{2}$ transition to ${ }^{5} \mathrm{D}_{0} \rightarrow{ }^{7} \mathrm{~F}_{1}$ means that the chemical environment symmetry around the $\mathrm{Eu}^{3+}$ ion is decreased $[37,38]$. From Table 2, it can be seen that, after 14 days of radiation, the ratio increased from 1.40 to 1.74 , then decreased to 1.68 , which may be attributed to the fact that, initially, the silane coating was cross-linked to form an Si-O network structure under ultraviolet light radiation. However, the layer structure is destroyed during long-term radiation exposure, and the coordination environment of the rare earth ions is changed back to its original state, only with a higher symmetry. From Figure 6, it can be indicated that the coating composites we prepared have an excellent fluorescence stability, and can transfer UV light to red light under long-term radiation exposure in order to protect the surface of wood from intense radiation.
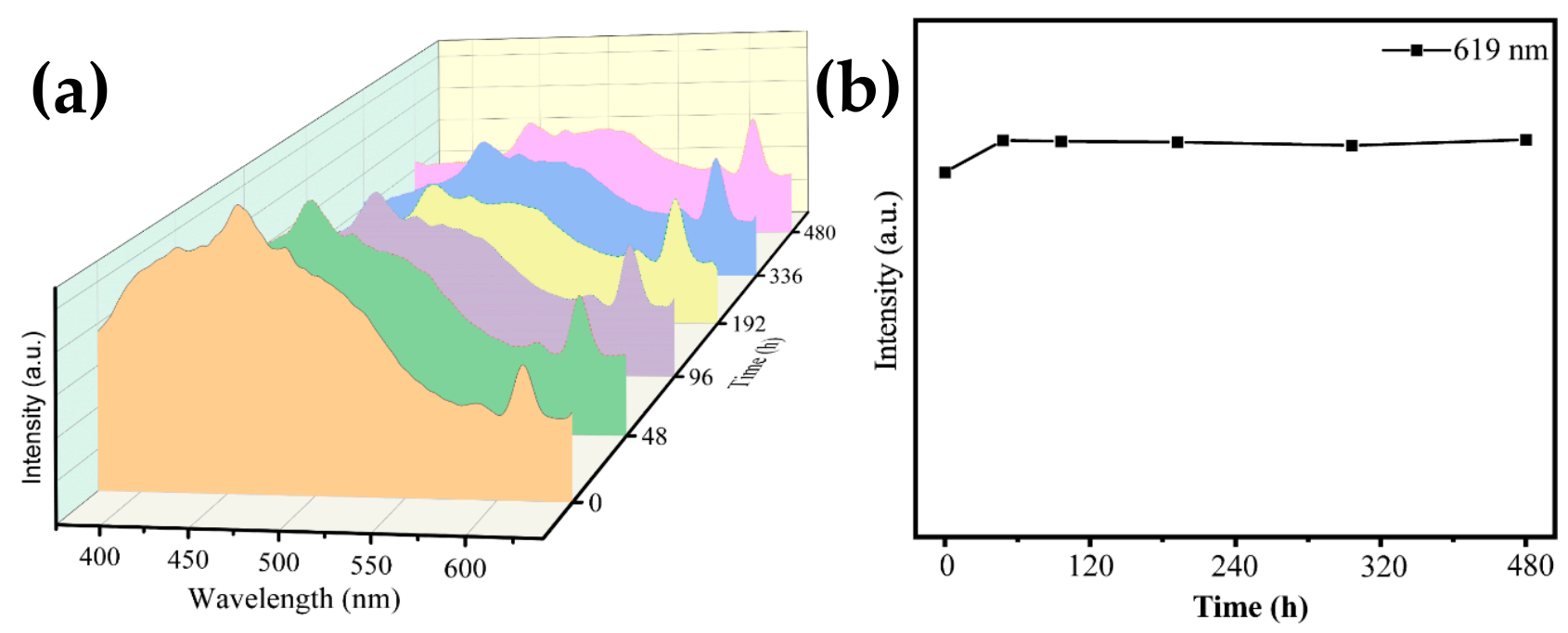

Figure 6. (a) Emission spectra of coating composite during the radiation of UV-light for different time (0 h, 48 h, 96 h, 192 h, $336 \mathrm{~h}, 480 \mathrm{~h})$ and (b) variation tendency of emission intensity $(614 \mathrm{~nm})$.

Table 2. The ratio of ${ }^{5} \mathrm{D}_{0} \rightarrow{ }^{7} \mathrm{~F}_{2} /{ }^{5} \mathrm{D}_{0} \rightarrow{ }^{7} \mathrm{~F}_{1}$ under different time radiation.

\begin{tabular}{ccccccc}
\hline Radiation Time (d) & $\mathbf{0}$ & $\mathbf{2}$ & $\mathbf{4}$ & $\mathbf{8}$ & $\mathbf{1 4}$ & $\mathbf{2 0}$ \\
\hline${ }^{5} \mathrm{D}_{0} \rightarrow{ }^{7} \mathrm{~F}_{2} /{ }^{5} \mathrm{D}_{0} \rightarrow{ }^{7} \mathrm{~F}_{1}$ & 1.40 & 1.51 & 1.62 & 1.70 & 1.74 & 1.68 \\
\hline
\end{tabular}




\section{Conclusions}

The prepared organic-inorganic hybrid silica coatings, based on natural wood materials, effectively improved the thermal stability and anti-ultraviolet aging ability of wood. Via TG analysis, the coated wood with the hybrid silica coatings was found to be able to extinguish flames, and the texture and structure of the residual chars was maintained, demonstrating the good efficiency of the coatings on wood at high temperatures, due to the formation of the $\mathrm{Si}-\mathrm{O}$ network, suggesting an evident intumescent charring mechanism for the coated woods. The coating composites also exhibit a better durability during 480 hours' radiation exposure using UV light $(340 \mathrm{~nm})$, which could be attribute to the fact that the silane coating was cross-linked to form an $\mathrm{Si}-\mathrm{O}$ network structure under ultraviolet light irradiation. More importantly, the formation of the $\mathrm{Si}-\mathrm{O}$ network structure increases the rigidity of the ligand and reduces the energy loss by non-radiative deactivation. Moreover, the coordination environment of the rare earth ions was changed back to its original state, only with a higher symmetry, which could enhance the energy transfer from the ligand to the rare earth ions in order to convert ultraviolet light into red light efficiently and reduce the damage caused by ultraviolet radiation on the coating composite, leading to a higher fluorescence stability. These hybrid silica coatings could therefore be considered as an effective and environmentally sustainable approach for the protection of wood.

Supplementary Materials: The following are available online at https:/ / www.mdpi.com/2073-4 360/13/1/127/s1, Figure S1: ESI-MS positive mode of organosilicon sol coordinated by europium (III) dissolved in THF showing the corresponding fragment inset, Figure S2: Geometry structures of products, Table S1: Fragments assignments according to the experimental data of organosilicon sol coordinated by europium (III).

Author Contributions: Conceptualization, R.H. and M.L.; writing-original draft preparation, M.L. and R.H.; writing-review and editing, D.W., M.L., and R.H.; supervision, D.W., M.L., Z.F., C.W. and J.L.; project administration, D.W.; funding acquisition, D.W. All authors have read and agreed to the published version of the manuscript.

Funding: This research was funded by the National Natural Science Foundation of China (GN: 31770593) and China Postdoctoral Science Foundation (GN: 160750).

Conflicts of Interest: The authors declare no conflict of interest.

\section{References}

1. Goodell, B.; Winandy, J.E.; Morrell, J.J. Fungal Degradation of Wood: Emerging Data, New Insights and Charging Perceptions. Coatings 2020, 10, 1210. [CrossRef]

2. Teo, K.T.; Hassan, A.; Gan, S.N. UV-Curable Urethane Acrylate Resin from Palm Fatty Acid Distillate. Polymers 2018, 10, 1374. [CrossRef]

3. Pánek, M.; Šimůnková, K.; Novák, D.; Dvořák, O.; Schönfelder, O.; Šedivka, P.; Kobetičová, K. Caffeine and TiO 2 Nanoparticles Treatment of Spruce and Beech Wood for Increasing Transparent Coating Resistance against UV-Radiation and Mould Attacks. Coatings 2020, 10, 1141. [CrossRef]

4. Kržišnik, D.; Lesar, B.; Thaler, N.; Humar, M. Influence of natural and artificial weathering on the colour change of different wood and wood-based materials. Forests 2018, 9, 488.

5. Cogulet, A.; Blanchet, P.; Landry, V. The Multifactorial Aspect of Wood Weathering: A Review Based on a Holistic Approach of wood Degradation Protected by Clear Coating. BioResources 2018, 13, 2116-2138. [CrossRef]

6. Zhu, H.; Luo, W.; Ciesielski, P.N.; Fang, Z.; Zhu, J.Y.; Henriksson, G.; Himmel, M.E.; Hu, L. Wood-Derived Materials for Green Electronics, Biological Devices, and Energy Applications. Chem. Rev. 2016, 116, 9305-9374. [CrossRef]

7. Frommen, C.; Sørby, M.H.; Heere, M.; Humphries, T.D.; Olsen, J.E.; Hauback, B.C. Rare Earth Borohydrides—Crystal Structures and Thermal Properties. Energies 2017, 10, 2115. [CrossRef]

8. Massi, M.; Ogden, M.I. Luminescent Lanthanoid Calixarene Complexes and Materials. Materials 2017, 10, 1369. [CrossRef]

9. Guo, G.; Wu, X.L.; Yan, X.Q.; Yan, L.; Li, X.F.; Zhang, S.W.; Qiu, N.N. Unprecedentedly High Activity and/or High Regio/Stereoselectivity of Fluorenyl-Based CGC Allyl-Type ฤ3: १1-tert-Butyl (dimethylfluorenylsilyl) amido Ligated Rare Earth Metal Monoalkyl Complexes in Olefin Polymerization. Polymers 2019, 11, 19.

10. Gan, W.; Gao, L.; Sun, Q.; Jin, C.; Lu, Y.; Li, J. Multifunctional wood materials with magnetic, superhydrophobic and antiultraviolet properties. Appl. Surf. Sci. 2015, 332, 565-572. [CrossRef] 
11. Hayoz, P.; Peter, W.; Rogez, D. A new innovative stabilization method for the protection of natural wood. Prog. Org. Coat. 2003, 48, 297-309. [CrossRef]

12. Patachia, S.; Croitoru, C.; Friedrich, C. Effect of UV exposure on the surface chemistry of wood veneers treated with ionic liquids. Appl. Surf. Sci. 2012, 258, 6723-6729. [CrossRef]

13. Liu, C.Z.; Mei, C.T.; Xu, B.; Chen, W.M.; Yong, C.; Wang, K.; Wu, Q.L. Light stabilizers added to the shell of co-extruded wood/highdensity polyethylene composites to improve mechanical and anti-UV ageing properties. $R$. Soc. Open Sci. 2018, 5, 180074. [CrossRef] [PubMed]

14. Salla, J.; Pandey, K.K.; Srinivas, K. Improvement of UV resistance of wood surfaces by using ZnO nanoparticles. Polym. Degrad. Stab. 2012, 97, 592-596. [CrossRef]

15. Han, W.-L.; Xu, Z.-P.; Wang, X.-Y.; Li, A. Mechanism of organic coating damage induced by ultraviolet radiation and its prevention measures. Pet. Eng. Constr. 2007, 4, 18-20.

16. Ma, M.; Chen, Q.; Wang, C.; Fu, H.; Li, T. High-performance organosilicon-refractory bauxite: Coating and fundamental properties. Constr. Build. Mater. 2019, 207, 563-571. [CrossRef]

17. Zhang, X.; Long, Z. Preparation and properties of tungsten-doped VO2 microcapsule intelligent temperature-control packaging paper. Prog. Org. Coat. 2019, 131, 219-226. [CrossRef]

18. Li, H.; Bao, H.; Bok, K.X.; Lee, C.; Li, B.; Zin, M.T.; Kang, L. High durability and low toxicity antimicrobial coatings fabricated by quaternary ammonium silane copolymers. Biomater. Sci. 2016, 4, 299-309. [CrossRef]

19. Zhang, C.; Huo, R.; Wang, X.; Zhang, J.; Cheng, J.; Shi, L. In-situ encapsulation of flaky aluminum pigment with poly (methylhydrosiloxane) anti-corrosion film for high-performance waterborne coatings. J. Ind. Eng. Chem. 2020, 86, 239-249. [CrossRef]

20. Suleiman, R.K.; Kumar, A.M.; Adesina, A.Y.; Al-Badour, F.A.; Meliani, M.H.; Saleh, T.A. Hybrid Organosilicon-Metal oxide Composites and their Corrosion Protection Performance for Mild Steel in 3.5\% NaCl Solution. Corros. Sci. 2020, $169,108637$. [CrossRef]

21. Zhao, X.; Hou, Z.; Wang, B.; Shen, Q.; Jia, H.; Zhang, A.; Liu, X.; Xu, B. Synthesis, luminance and ultraviolet resistance of a copolymer phosphor of Eu-complex and siloxane in near UV-based LED. Res. Chem. Intermed. 2017, 43, 4129-4143. [CrossRef]

22. Qiao, Q.; Shen, Z.Q.; Wu, X.S.; Wang, X.Z.; Pei, W.B.; Liu, S.X.; Ren, X.M. Glowing kaolinite intercalated with N-Methyl imidazole and $\mathrm{Eu} 3+/ \mathrm{Tb} 3+$ salts and potential application in UV-to-red light conversion. Appl. Clay Sci. 2020, 186, 105473. [CrossRef]

23. Zhou, Q.; Dong, X.L.; Xiong, Y.X.; Zhang, B.B.; Lu, S.; Wang, Q.; Liao, Y.G.; Yang, Y.J.; Wang, H. Multi-Responsive LanthanideBased Hydrogel with Encryption, Naked Eye Sensing, Shape Memory, Self-Healing, and Antibacterial Activity. ACS Appl. Mater. Interfaces 2020, 12, 28539-28549. [CrossRef] [PubMed]

24. Wang, M.X.; Yang, C.H.; Liu, Z.Q.; Zhou, J.; Xu, F.; Suo, Z.; Yang, J.H.; Chen, Y.M. Tough Photoluminescent Hydrogels Doped with Lanthanide. Macromol. Rapid Commun. 2015, 36, 465-471. [CrossRef] [PubMed]

25. Sabarinathan, P.; Rajkumar, K.; Annamalai, V.E.; Vishal, K. Characterization on chemical and mechanical properties of silane treated fish tail palm fibres. Int. J. Biol. Macromol. 2020, 163, 2457-2464. [CrossRef] [PubMed]

26. Célino, A.; Fréour, S.; Jacquemin, F.; Casari, P. Characterization and modeling of the moisture diffusion behavior of natural fibers. J. Appl. Polym. Sci. 2013, 130, 297-306. [CrossRef]

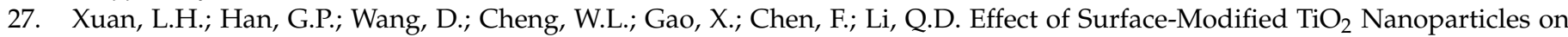
the Anti-Ultraviolet Aging Performance of Foamed Wheat Straw Fiber/Polypropylene Composites. Materials 2017, $10,456$. [CrossRef]

28. Jiang, T.; Kuila, T.; Kim, N.H.; Lee, J.H. Effects of surface-modified silica nanoparticles attached graphene oxide using isocyanateterminated flexible polymer chains on the mechanical properties of epoxy composites. J. Mater. Chem. A 2014, 2, 10557-10567. [CrossRef]

29. Zhang, W.; Wang, H. Preparation and luminescent properties of lanthanide $\left(\mathrm{Eu}^{3+}\right.$ and $\left.\mathrm{Tb}^{3+}\right)$ complexes grafted to 3aminopropyltriethoxysilane by covalent bonds. Opt. Mater. 2015, 50, 208-214. [CrossRef]

30. Devi, R.R.; Maji, T.K. Interfacial effect of surface modified $\mathrm{TiO}_{2}$ and $\mathrm{SiO}_{2}$ nanoparticles reinforcement in the properties of wood polymer clay nanocomposites. J. Taiwan Inst. Chem. Eng. 2013, 44, 505-514. [CrossRef]

31. Yang, Y.; Shen, H.; Qiu, J. Fabrication of biomimetic robust self-cleaning superhydrophobic wood with canna-leaf-like micro/nanostructure through morph-genetic method improved water-, UV-, and corrosion resistance properties. J. Mol. Struct. 2020, 1219, 128616. [CrossRef]

32. Zhao, Z.; Huang, C.; Wu, D.; Chen, Z.; Zhu, N.; Gui, C.; Zhang, M.; Umemura, K.; Yong, Q. Utilization of enzymatic hydrolysate from corn stover as a precursor to synthesize an eco-friendly plywood adhesive. Ind. Crop. Prod. 2020, 152, 112501. [CrossRef]

33. Zhang, A.; Wang, Z.; Hong, W.; Zhang, Y.; Guo, J.; Wang, Y.; Miao, Y.; Jia, H.; Wang, H. Synthesis, characterization and the fluorescent enhancement mechanism of bonded poly (Eu(TTA) $)_{2}$ (phen) MAA-co-VA) nanofibers by electrospinning. Opt. Mater. 2020, 106, 110007. [CrossRef]

34. Li, Y.; Xie, D.; Pang, X.; Yu, X.; Yu, T.; Ge, X. Highly selective fluorescent sensing for fluoride based on a covalently bonded europium mesoporous hybrid material. Sens. Actuators B Chem. 2016, 227, 660-667. [CrossRef]

35. Singh, K.; Banerjee, S.; Patra, A.K. Photocytotoxic luminescent lanthanide complexes of DTPA-bisamide using quinoline as photosensitizer. RSC Adv. 2015, 5, 107503-107513. [CrossRef]

36. Kumar, K.S.; Schäfer, B.; Lebedkin, S.; Karmazin, L.; Kappes, M.M.; Ruben, M. Highly luminescent charge-neutral europium (iii) and terbium (iii) complexes with tridentate nitrogen ligands. Dalton Trans. 2015, 44, 15611-15619. [CrossRef] 
37. Huang, L.B.; Cheng, L.H.; Yu, H.Q.; Zhang, J.S.; Zhou, L.; Sun, J.S.; Zhong, H.Y.; Li, X.P.; Tian, Y.; Zheng, Y.F.; et al. Electrospinning preparation and optical transition properties of $\mathrm{Eu}(\mathrm{DBM}) 3 \mathrm{Phen} / \mathrm{PS}$ fluorescent composite fibers. Opt. Commun. 2012, 285, 1476-1480. [CrossRef]

38. Kumar, B.; Kaur, G.; Rai, S.B. Sensitized green emission of terbium with dibenzoylmethane and 1, 10 phenanthroline in polyvinyl alcohol and polyvinyl pyrrolidone blends. Spectrochim. Acta. A 2017, 187, 75-81. [CrossRef] 